AA Soliman, AB Ali, MA Fathy, NT Elmeligy. Pediatric, Assiut University, Assiut, Egypt

Background Early diagnosis and treatment of vesicoureteral reflux (VUR) means prevention of $25 \%$ of cases of chronic renal impairment (CRI) which is due to reflux nephropathy.

Aim of the work This work was planned to correlate the levels of some urinary and serum biomarkers with traditional methods of diagnosis of reflux and reflux nephropathy.

Materials and Methods We evaluated urinary concentrations of IL-8 in 145 children. 105 children of them were selected from those who were diagnosed to have vesicoureteral reflux (study group). The other 40 children were apparently healthy children to serve as normal control (control group).

40 cases of the study group were randomly selected, DEMSA scan was done for them. Basic fibroblast growth factor (b-FGF) was estimated in the serum of these 40 cases.

Results Urinary IL-8 concentrations were significantly higher in study group than in control group. There was a highly significant difference in level of serum b-FGF between those with renal scarring and those without scarring.

Conclusion Urinary IL-8 can be used as a promising diagnostic marker for VUR. Also, it is appropriate to measure serum b-FGF in sera of those with reflux to determine if renal parenchymal damage (scarring) is present and of which grade.

\section{VESICOURETERAL REFLUX AND URODYNAMIC DYSFUNCTION}

doi:10.1136/archdischild-2012-302724.1209

'D Batinic, ${ }^{2} \mathrm{D}$ Milosevic, ${ }^{3} \mathrm{M}$ Topalovic-Grkovic, 'L Nizic, ' $\mathrm{K}$ Vrljicak, 'M Lemac, 'D Turudic. 'Department of Pediatric Nephrology, Universitary Hospital Center; ${ }^{2}$ Department of Pediatric Nephrology, University Hospital Center; ${ }^{3}$ Department of Anestesiology and Intensive Care, University Hosptal Center, Zagreb, Croatia

The concept of vesicoureteral reflux (VUR) as a consequence of a congenital anomaly of the vesicoureteral junction have undergone changes owing to the finding that such children may have a lower urinary tract dysfunction, which produces a high intravesical pressure and consequently a predisposition for VUR. We investigated relationship of VUR and urodynamics. The urodynamics was investigated by pressure-flow-EMG study in 132 children with primary VUR and 162 refluxing units. Only 33 (25.0\%) patients had normal urodynamic finding. The most frequent pathological finding was overactive bladder (OAB), found in 59 (44.7\%) children, followed by dysfunctional voiding (DV) in 25 (18.9\%) children. The children with VUR grades I and II had higher percentage of pathological urodynamic findings than children with VUR grades III and IV. OAB was more frequent in children under 5 years of age, with unilateral and lower grades VUR. It was found equaly in children with and without uroinfections. DV was more frequent in children older than 5 years, with bilateral VUR, higher grades VUR and uroinfections. The results of our study show that the children with VUR have high incidence of urodynamic disoders and indicate the possible role of urodynamic dysfunction in the pathogenesis of VUR, especially the mild ones. They also indicate the need for incorporating urodynamic investigation in the evaluation of children with VUR.

\section{URINARY STONE DISEASE IN CHILDREN- A SINGLE CROATIAN CENTER EXPERIENCE}

doi:10.1136/archdischild-2012-302724.1210

'D Milosevic, 'D Batinic, '2M Topalovic-Grkovic, 'L Nizic, 'K Vrljicak, 'M Lemac, 'D Turudic, 'AT Golubic. 'Department of Pediatric Nephrology; ${ }^{2}$ Department of Anestesiology and Intensive Care, Universitary Hospital Center, Zagreb, Croatia
Urinary stone disease is not so rare in children. The aim of this study was to assess the demographic, clinical and biological characteristics, as well as outcome, of urinary stone disease among Croatian children. We reviewed medical records of 76 children from various parts of Croatia who were diagnosed with urinary stone disease from 2002-2011. The average age (mean) were 9 yr 7 mo (toddlers $7.89 \%$ ) with approximately equal gender distribution (male $53.95 \%$ vs female $46.05 \%$ ). Family affection was identified in $27(35.53 \%)$ children with the predominance of female transmission. The most stones were made of $\mathrm{Ca}$ oxalate dihydrate and monohydrate (75\%). Hypercalciuria were detected in $47.37 \%$, mild hyperoxaluria in $(13.16 \%)$, hypocitraturia in $1.31 \%$ and $38.16 \%$ remained of idiopathic origin. Urine saturation (EQUIL 2) were above the limits in $47(61.84 \%)$ children, urine volume less than average in 12 (15.79\%). For most of the children we recommended increased fluid intake and balanced food nutrition, citrate were administered in 20 (26.32\%), thiazides in 10 (13.15\%) and aldactone in $1(1.31 \%)$. Spontaneous evacuation were noticed in $51.32 \%$, surgical (operation and endoscopic removal) $11.84 \%$, ESWL in 11 $0.84 \%$, spontaneous resolution (ceftriaxone) in $1(1.31 \%)$ and in $13.16 \%$ the stone was not removed from urinary tract. The study gave insight in etiology of urinary stone disease in Croatian children. Main pathological factors were hypercalciuria, mild hyperoxaluria and increased urine saturation. Spontaneous evacuation of stones were notified for most of chldren.

\section{CYCLOSPORINE A IN THE TREATMENT OF RESISTANT CHILDHOOD NEPHROTIC SYNDROME}

doi:10.1136/archdischild-2012-302724.1211

L Sfaihi, S Kmiha, I Maaloul, H Aloulou, I Chabchoub, T Kamoun, M Hachicha. CHU Hedi Chaker, Sfax, Tunisia

Background In children, idiopathic nephrotic syndrome is primarily treated using corticosteroids. When remission is not achieved, the administration of potent immunosuppressant therapy becomes imperative. Cyclosporine A (CsA) is reportedly associated with a higher incidence of remission in comparison with other immunosuppressive agents. The aim of our study is to evaluate the efficiency of cyclosporin A (CyA) therapy in 11 children treated with resistant nephrotic syndrome.

Methods Eleven children enrolled in this study were all hospitalized with resistant nephrotic syndrome, aged 1 to 11 years (average $5.8 \mathrm{yrs}$ ) and included 7 males and 4 females. CyA was given to each patient with dosage of $5 \mathrm{mg} / \mathrm{kg} /$ day during the corticosteroid was diminished. The renwal biopsy was performed in all patients before the administration of CyA.

Results Eleven children with resistant nephrotic syndrome of different pathological types were treated with CyA, including 3 cases of minimal change nephrotic syndrome (MCNS), 2 cases of mesangioproliferative glomerulonephritis (MsPGN), 1 case of extra membranous glomerulonephritis (EMGN) and 5 cases of focal segmental glomerular sclerosis (FSGS).

Three patients got complete remission, seven patients developed chronic renal insufficiency and one had no change after four month treatment with CyA. The overall response rate was $27 \%$. Patients with different renal pathological types showed different responses. The FSGS cases showed the lowest rate.

Conclusion CyA has limited efficiency in patients with steroidresistant nephrotic syndrome. CyA should be used cautiously because of the potential for CyA nephrotoxicity.

\section{2 GITELMAN SYNDROME IN A SPANISH GYPSY PAEDIATRIC} PATIENT MUTATION INTRON $9+\mathbf{1 G}>\mathbf{T}$

doi:10.1136/archdischild-2012-302724.1212 
'B Orive, ${ }^{2} \mathrm{~J}$ Montiano, ${ }^{2} \mathrm{C}$ Salado, ${ }^{3} \mathrm{~A}$ Torrents. ${ }^{1}$ Pediatric Nephrology; ${ }^{2}$ Pediatrics, Hospital Universitario de Álava, Vitoria; ${ }^{3} G e n e t i c s$, Reference Laboratory, Barcelona, Spain

Introduction Gitelman syndrome is an inheredited tubular disorder characterized by metabolic alkalosis, hypokaliemia and hypomagnesemia of renal origin and hypocalciuria. The majority of patients with Gitelman syndrome carry inactivating mutations in the SLC 12A3 gene encoding the sodium- chloride cotransporter located in the distal convoluted tubule. The purpose of this report is to describe a new mutation of the SLC12A3 gene in a gypsy boy, mutation of ancient origin that would be specific in this ethnic group and spread throughout Europe.

Case Report A 5 years old male children of Roma origin (Gypsy) was referred to our hospital because asthenia, muscle weakness and hypokaliemia. Both parents are healthy, non consanguineous with normal serum potassium. There were no other family members affected. Relevant biochemical data at diagnosis was: Serum: $\mathrm{pH}$ 7.52, bicarbonate $31 \mathrm{mmol} / \mathrm{L}$, potassium $2 \mathrm{mEq} / \mathrm{L}$, sodium 136 $\mathrm{mEq} / \mathrm{L}$, chloride $97 \mathrm{mEq} / \mathrm{L}$, magnesium $1.6 \mathrm{mg} / \mathrm{dl}$, creatinine $0.4 \mathrm{mg} /$ dl, calcium 9 mg/dl. Plasma Renin Activity 13.3 ng/ml/h, Aldosterone $138 \mathrm{pg} / \mathrm{ml}$.

Urinary potassium $51 \mathrm{mEq} / \mathrm{L}$, calcium/creatinine ratio 0.12 ; Potassium fraccional excretion $20.4 \%$, magnesium fractional excretion $5.9 \%$. Renal ultrasonography and blood pressure was normal.

Genetic study was performed: the patient was homozygous for splice site mutation guanidine to thymine in the first position of intron 9 of SLC12A3 gene (intron $9+1 \mathrm{G}>\mathrm{T}$ ).

Conclusion This finding will facilitate the identification of the genetic defect in further cases of Gitelman syndrome among the gypsy population. This patients exhibit muscle syntoms and asthenia althroug the disease is not particulary severe in this ethnic group.

\section{A BOY WITH HYPERKALEMIA AND HYPERTENSION WITHOUT FAMILY HISTORY: STILL PSEUDOHYPOALDESTERONISM (GORDON SYNDROME)?}

doi:10.1136/archdischild-2012-302724.1213

'RA Hollander, ${ }^{1} \mathrm{D}$ Trouet, ${ }^{2} \mathrm{G}$ Mortier. ${ }^{1}$ Pediatric Nephrology; ${ }^{2}$ Medical Genetics, Antwerp University Hospital, Edegem (Antwerp), Belgium

Background and Aims We report a 6-year-old boy presenting with macroscopic hematuria, hyperkalemia and hyperfosfatemia.

Results A 6-year-old boy presented to our outpatient clinic with hematuria. No clinical abnormalities were found, besides borderline hypertension of $120 / 60 \mathrm{mmHg}$ (P95 adjusted for height and age 100/57). Laboratory testing revealed a serum potassium of 8.6 $\mathrm{mmol} / \mathrm{l}$ and a phosphate of $6.2 \mathrm{mg} / \mathrm{dl}$. During admission hyperkalemia appeared refractory to standard treatment with furosemide, salbutamol and alkalinisation. Prompt reduction of hyperkalemia was observed after a trial with hydrochlorothiazide, suggesting the diagnosis of pseudohypoaldesteronism. Further testing revealed a high aldosteron of $537 \mathrm{pg} / \mathrm{ml}$. Familial history was negative but still a suspicion of pseudohypoaldosteronim remained, so genetic testing was performed. A de novo splice site mutation was found in the CUL3-gene (c.1377+1G>A) leading to a skipping of exon 9 .

Conclusions We present an atypical presentation of Gordon syndrome (familial hyperkalemic hypertension) due to a de novo splice mutation. The clinician should be aware of this possibility when facing a child with high serum potassium.

\section{SEVERE RICKETS AND HYPOKALEMIC FLACCID PARALYSIS DUE TO DISTAL RENAL TUBULAR ACIDOSIS (DRTA) IN A 4-YEAR-OLD GIRL}

JD Martinez-Pajares, 0 Diaz-Morales, J Trigo-Moreno, JC Ramos-Diaz, M MirandaValdivieso, E Fernandez-Gomez. UGC Pediatria, Hospital Comarcal de Antequera, Antequera, Spain

Background dRTA is a tubulopathy characterized by metabolic acidosis with normal anion gap secondary to a defective secretion of $\mathrm{H}+$ ions by the collecting tubule. This anomaly leads to an inability to acidify the urine during systemic acidemia. There are more than 50 different mutations, with an autosomal recessive or dominant pattern of transmission. Clinical features usually appear from two years of age as vomiting, dehydration and failure to thrive, although the first signs may be present from the first weeks of life. In recessive forms can be associated with sensorineural deafness. The prognosis is favorable if alkali replacement is performed properly. However, urolithiasis, nephrocalcinosis and chronic renal failure may appear if the diagnosis is delayed or the treatment is inadequate.

Case Report We report a 4-year-old Morrocan girl with a history from the first months of life characterized by failure-to-thrive, hyporexia, polydipsia and polyuria, and delayed motor function. In recent months she was unable to ambulate due to progressive muscle weakness, especially of the lower limbs. Physical findings included a severe weight and height delay, signs of severe malnutrition and rickets, and tachypnea. Laboratory findings were consistent with distal renal tubular acidosis (metabolic acidosis with normal anion gap, severe hypokaliemia, hypophosphatemia, mild hypocalcemia, and hypouricemia, with urinary $\mathrm{pH}>6$ and positive urinary gap). Also, bilateral renal nephrocalcinosis was found. Alkali replacement was able to correct the electrolytic abnormalities and promote catch-up.

Comments dRTA must be suspected in the presence of the clinical and laboratory findinds reported.

\section{REFERENCE VALUES OF SERUM CYSTATIN C IN VERY LOW BIRTH WEIGHT PREMATURE INFANTS}

doi:10.1136/archdischild-2012-302724.1215

${ }^{1} \mathrm{G}$ Demirel, ${ }^{1} \mathrm{HH}$ Celik, 'FE Canpolat, ${ }^{2} \mathrm{O}$ Erdeve, ${ }^{3} \mathrm{Z}$ Biyikli, 1,4 $\mathrm{U}$ Dilmen. 'Neonatology; ${ }^{2} Z$ Zekai Tahir Burak Maternity and Teaching Hospital; ${ }^{3}$ Biostatistics, Ankara University; ${ }^{4}$ Pediatrics, Yildirim Beyazit University, Faculty of Medicine, Ankara, Turkey

Background and Aims To determine reference values for cystatin $\mathrm{C}(\mathrm{Cys} \mathrm{C})$ and its correlation with creatinine (Cr), gestational age, birth weight and maternal $\mathrm{Cr}$ status in very low birth weight (VLBW) preterm infants.

Aims The study included 113 VLBW premature infants $(<1500 \mathrm{~g})$ of $\leq 32$ gestational week.

Results The mean level of CysC was $1.77 \pm 0.38 \mathrm{mg} / \mathrm{L}$ on day 1 and $1.61 \pm 0.37 \mathrm{mg} / \mathrm{L}$ on day 3 , and the decrease was statistically significant. There was a significant correlation only between maternal $\mathrm{Cr}$ and first-day $\mathrm{Cr}$ values and negative correlations between $\mathrm{Cr}$ and gestational age and birth weight on third day. Creatinine was not correlated with CysC both on day 1 ( $r=-0.077, \mathrm{p}=0.417)$ and day $3(\mathrm{r}=0.132$, $\mathrm{p}=0.164)$. The reference values of Cys $C$ at birth are [median (3p-97p)] $1.8 \mathrm{mg} / \mathrm{dl}(0.8-2.2)$ for 24-26 weeks, $1.8 \mathrm{mg} / \mathrm{dl}(1.51-3.19)$ for 26-28 weeks, $1.8 \mathrm{mg} / \mathrm{dl}(0.65-2.48)$ for 28-30 weeks and $1.79 \mathrm{mg} / \mathrm{dl}(0.68$ 2.31) for 30-32 weeks and at 3rd days are $1.5 \mathrm{mg} / \mathrm{dl}(0.54-2.0)$ for 24-26 weeks, $1.61 \mathrm{mg} / \mathrm{dl}$ (1.1-3.4) for 26-28 weeks, $1.7 \mathrm{mg} / \mathrm{dl}(0.56$ 2.3) for 28-30 weeks and $1.6 \mathrm{mg} / \mathrm{dl}(0.92-2.21)$ for 30-32 weeks.

Conclusion CysC offer an important advantage in the measurement of renal functions independent from gestational age, birth weight and maternal Cr status in VLBW preterm infants.

\section{INTRAUTERINE GROWTH RESTRICTION AND DEVELOPMENTAL PROGRAMMING OF RENAL DISEASE}

doi:10.1136/archdischild-2012-302724.1216 